\title{
CMR myocardial tissue characterization in a mouse model of doxorubicin-induced cardiotoxicity
}

Bradley D Allen ${ }^{1 *}$, Micah Anderle ${ }^{1}$, Sol Misener ${ }^{1}$, Gillian Murtagh ${ }^{1}$, Nicholas Furiasse ${ }^{2}$, Nausheen Akhter $^{2}$, Daniele Procissi ${ }^{1}$, James C Carr ${ }^{1}$

From 18th Annual SCMR Scientific Sessions

Nice, France. 4-7 February 2015

\section{Background}

Cardiotoxicity is a major limiting factor preventing dose-effective use of multiple cytotoxic agents in cancer treatment. Current cardiotoxicity diagnosis is based on functional changes that occur late in the course of the disease. In this pre-clinical pilot study, we hypothesize myocardial T1 and T2 mapping will identify mice at risk of death secondary to doxorubicin-induced cardiotoxicity prior to cardiac function deterioration.

\section{Methods}

Eleven healthy, 10-week-old C57BL/6 female mice were included in the study. All procedures are in accordance with an Institutional Animal Care and Use Committee approved protocol. Doxorubicin-induced cardiotoxicity was generated by giving $8 \mathrm{mg} / \mathrm{kg}$ of doxorubicin via intraperitoneal (IP) injection weekly for 4 weeks in $n=8$ randomly selected mice. A control group of $n=3$ mice was given a weekly volume equivalent dose of IP normal saline. Each mouse underwent ECG-gated CMR on a 7T small animal scanner (ClinScan, Bruker, Billerica, MA) prior to treatment, at 2 weeks, and post-treatment. Steady-state free precession images were acquired at the left ventricular base, mid-ventricle, and apex and ejection fraction (EF) was calculated (Figure 1). Gadopentetate Dimeglumine contrast was injected via the tail vein at a dose of $1 \mathrm{~mL} / \mathrm{kg}$. Myocardial T1 and T2 maps were generated using dedicated offline software to calculate the pixel-wise relaxation

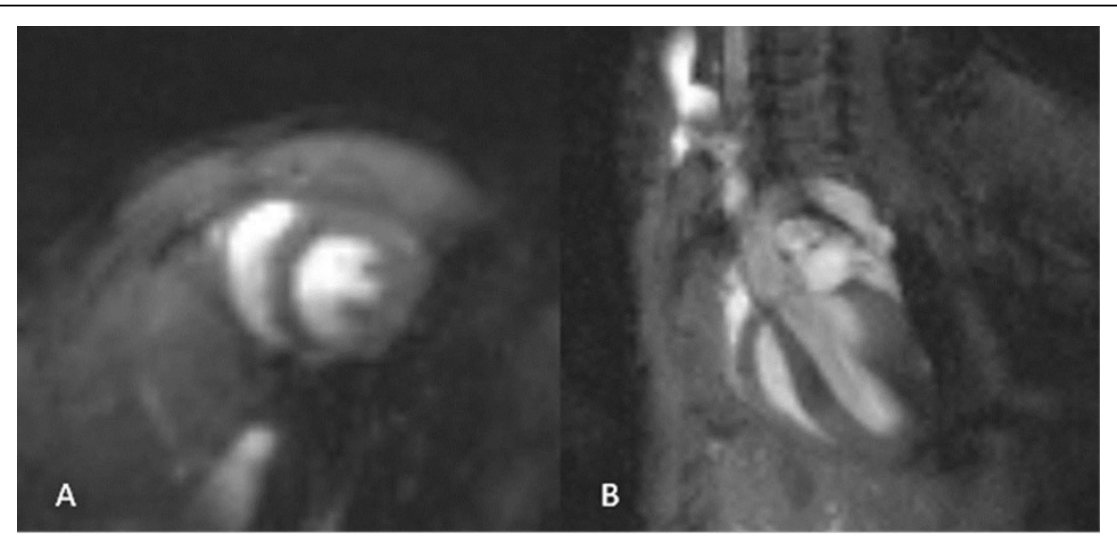

Figure 1 Cardiac MR at 7 Tesla in a mouse model of cardiotoxicity. Representative short axis (A) and 3-Chamber (B) balanced steady-state free precession (bSSFP) cine images. The short axis images acquired at multiple slices along the left ventricle are used to calculate ejection fraction as an assessment of cardiac function.

${ }^{1}$ Radiology, Northwestern University, Chicago, IL, USA

Full list of author information is available at the end of the article 


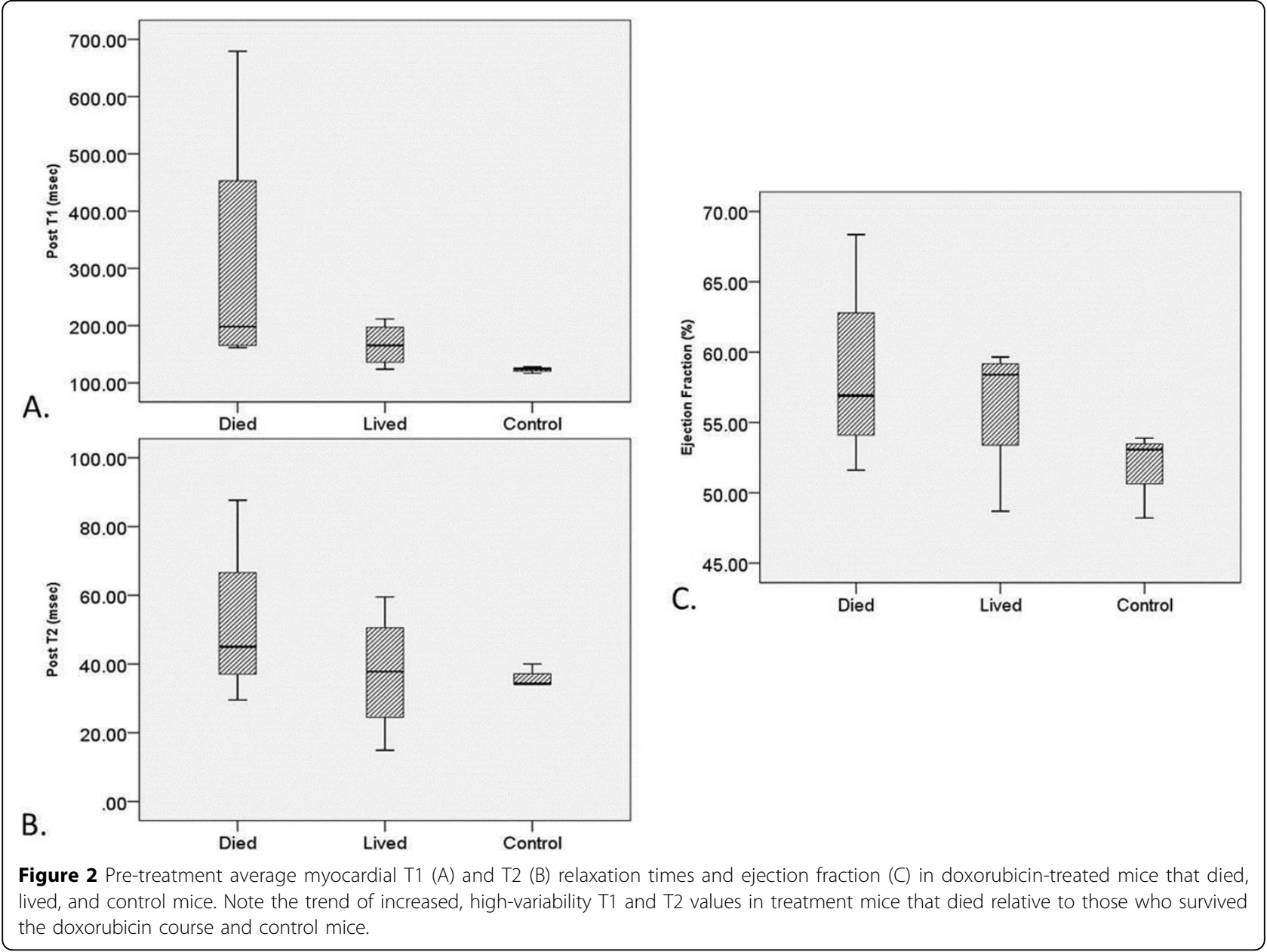

times at a mid-left ventricle short axis slice. An inversion recovery sequence with variable flip angles $\left(\alpha=3^{\circ}, 6^{\circ}, 10^{\circ}\right.$, $16^{\circ}$, and $25^{\circ}$ ) was used for T1 mapping and a spin-echo sequence with varied echo times (TE $=7 \mathrm{~ms}, 14 \mathrm{~ms}, 21$ $\mathrm{ms}, 28 \mathrm{~ms}$ ) was used for T2 mapping. Average myocardial $\mathrm{T} 1$ and $\mathrm{T} 2$ relaxation times and ejection fraction were compared between mice that died during treatment, survived to the end of treatment, and controls using repeated measure linear modeling.

\section{Results}

In the treatment group, $n=4$ mice survived and $n=4$ mice died during treatment. All control mice survived. Linear modeling demonstrated a significant relationship between $\mathrm{T} 2$ relaxation times and outcome when controlling for pre-, intra-, or post-treatment scan $(\beta=-0.008$, $p$ $=0.02)$. T1 $(\beta=-0.001, \mathrm{p}=0.10)$. and $\mathrm{EF}(\beta=-0.015, \mathrm{p}=$ $0.09)$ did not demonstrate a significant relationship. There was a non-significant trend of increased pre-treatment myocardial T1 $(309 \pm 248 \mathrm{~ms}$ vs. $167 \pm 38 \mathrm{~ms}, \mathrm{p}=0.29)$ and T2 (52 $\pm 25 \mathrm{~ms}$ vs. $38 \pm 19 \mathrm{~ms}, \mathrm{p}=0.49)$ in mice who died compared to those who survived. EF doesn't show the same trend ( $58 \pm 7 \%$ vs. $56 \pm 5 \%$ ). (Figure 2)

\section{Conclusions}

Average myocardial T2 in mice undergoing IP chemotherapy was significantly correlated with outcome, while T1 and EF showed no correlation. The trends identified in this pre-clinical pilot study further drive the hypothesis that myocardial tissue characterization may be an effective tool for diagnosis and risk-stratification of chemotherapy-induce cardiotoxicity.

\section{Funding}

Northwestern CTI Pilot Grant, NIH/NCI R25 CA 132822 .

\section{Authors' details}

${ }^{1}$ Radiology, Northwestern University, Chicago, IL, USA. ${ }^{2}$ Medicine-Cardiology, Northwestern University, Chicago, IL, USA. 

and take full advantage of:

- Convenient online submission

- Thorough peer review

- No space constraints or color figure charges

- Immediate publication on acceptance

- Inclusion in PubMed, CAS, Scopus and Google Scholar

- Research which is freely available for redistribution 